\title{
Recent Developments in EU and US Pharmacovigilance Legislation
}

Gianluca Montanari-Vergallo*

Department of Anatomical, Histological, Medico-Legal and Locomotive Apparatus Sciences, Faculty of Pharmacy and Medicine, "Sapienza" University of Rome, Italy

\begin{abstract}
The evolution of EU and US pharmacovigilance legislation highlights two trends. The first is to strengthen the instruments of protection of human health through, inter alia, the continuous monitoring of the risk-benefit ratio of drugs, greater transparency and the power to penalize producers for the failure to meet the pharmacovigilance obligations. The second trend manifests the partial harmonization of the different pharmacovigilance systems. However, this goal is still far away. In order to achieve it would be necessary to establish an identical definition of adverse drug reaction in both the EU and US legislation.
\end{abstract}

Keywords: Pharmacovigilance systems; Legislation; European Union; United States of America

Abbreviations: ADR: Adverse Drug Reaction; EMA: European Medicines Agency; MAH: Marketing Authorization Holder; PRAC: Pharmacovigilance Risk Assessment Committee; PSUR: Periodic Safety Update Report; REMS: Risk Evaluation and Mitigation Strategy; RMP: Risk Management Plan

\section{Introduction}

According to the European Commission's data, a) $5 \%$ of all hospital admissions are due to ADR; b) $5 \%$ of all hospital patients experience an ADR; c) on average, ADRs cause at least 1.91 extra days of hospitalization; d) ADRs are the 5th most common cause of hospital death [1]. Also in the United States, ADRs contribute to more than 100.000 deaths annually and are among the top 10 leading causes of death [2]. This situation makes clear the importance of pharmacovigilance, as "the science and activities relating to the detection, assessment, understanding and prevention of adverse effects or other drug related problems" [3].

\section{EU Legislation}

With four different Acts [4-7] over the last two years, the E.U. has introduced several changes [8-10]. For example, now:

a. The definition of ADR has been amended to ensure that it covers noxious and unintended effects resulting also from medication errors and uses outside the terms of the marketing authorization, including the misuse and abuse of the medicinal product. A reasonable possibility of causal relationship between a medicinal product and an adverse event is sufficient reason for reporting;

b. The competent authorities are empowered to impose on MAHs the obligation to conduct post-authorization studies on safety and on efficacy, as a condition of the marketing authorization;

c. Some medicinal products, e.g. all medicinal products with a new active substance and biological medicinal products, including biosimilars, are authorized subject to additional monitoring; the EMA keeps up to date a publicly available list of these medicinal products, which have to be identified by a black symbol;

d. MAH is responsible for continuously monitoring the safety of its drugs, for ensuring that the product information is kept up to date, and for informing the authorities of any changes that might impact on the marketing authorization, also with regard to off label use; e. In order to simplify the reporting of suspected ADR, the MAHs and the Member States have to report those reactions only to the Union pharmacovigilance database, called "Eudravigilance";

f. In order to increase the level of transparency, the Member States have to create and maintain medicines web-portals;

g. Obligations imposed for PSURs are proportionate to the risks posed by medicinal products;

h. The Member States apply to MAHs effective, proportionate and dissuasive penalties for non-compliance with pharmacovigilance obligations;

i. PRAC is a new scientific committee within the EMA, created to ensure access to the best scientific and medicinal expertise for the evaluation of the safety of medicines and risk minimization measures, with the ultimate goal of reducing ADRs;

j. A new tool, called the "Pharmacovigilance System Master File", is aimed to contribute to the appropriate planning and conduct of audits by the MAH and the supervision of pharmacovigilance activities by the qualified person responsible for pharmacovigilance;

k. MAHs, national competent authorities and EMA have to establish an adequate and effective quality system, which provides for an effective monitoring of compliance and the accurate and proper documentation of all measures taken. The quality system also ensures that MAHs, national competent authorities and EMA have at their disposal sufficient competent, appropriately qualified and trained staff;

1. MAHs, national competent authorities and EMA have to continuously monitor the data in the Eudravigilance database

*Corresponding author: Gianluca Montanari-Vergallo, Department of Anatomical Histological, Medico-Legal and Locomotive Apparatus Sciences, Faculty of Pharmacy and Medicine, "Sapienza" University of Rome, 336 Viale Regina Elena, Rome 00161, Italy, Tel: +39.0649912620; Fax: +39.0664465419; E-mail: gianluca. montanarivergallo@uniroma1.it

Received December 21, 2012; Accepted January 08, 2013; Published January 10,2013

Citation: Montanari-Vergallo G (2013) Recent Developments in EU and US

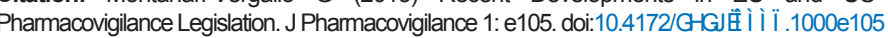

Copyright: (c) 2013 Montanari-Vergallo G. This is an open-access article distributed under the terms of the Creative Commons Attribution License, which permits unrestricted use, distribution, and reproduction in any medium, provided the original author and source are credited. 
to determine whether the risk-benefit balance of the medicinal product is changed;

m. All new marketing authorization application have to contain a RMP with a detailed description of the risk management system used by the MAH;

n. The list of medicinal products subject to additional monitoring will systematically include medicinal products that are subject to certain post-authorization safety conditions;

o. In order to properly address in all Member States concerns relating to the risks or benefits of a medicinal product authorized in the Union, MAHs will be obliged to inform the EMA of the reasons for withdrawing or interrupting the placing on the market of a drug, for requesting the revocation of the marketing authorization, or for not renewing it.

\section{US Legislation}

Also U.S. legislation has been significantly enhanced by the Title IX of the Food and Drug Administration Amendments Act of 2007 [11]. As a result, FDA:

a. Conduct a bi-weekly screening of the Adverse Event Reporting System database and post a quarterly report, available on internet, of any new safety information or potential signal of a serious risk;

b. Is empowered to require the company to submit a REMS, when it is not sure that the benefits of its product outweigh the risks;

c. Is entitled to require post-approval studies or trials to assess a known risk or signals of serious risk and to identify unexpected serious risk emerging from available data, if the existing information is not sufficient to fulfill this assessment;

d. Has authority to sanction with civil penalties and the misbranding of the drug all applicants who violate duties related to REMS requirements or post-approval studies/trials [12].

\section{Conclusions}

Therefore, EU and US legislations primarily tend toward the intensification of pharmacovigilance, moving from passive to proactive, although the usefulness of the tools provided by the legislation is controversial [13-18]. The second trend is a partial harmonization of the different pharmacovigilance systems in order to simplify the sponsors' activities and increase the efficacy of pharmacovigilance $[19,20]$. The International Conference on Harmonization of Technical Requirements for Registration of Pharmaceuticals for Human Use (ICH) has elaborated a pharmacovigilance guideline for medicines approved in the U.S., the E.U. and Japan [21]. Moreover, these systems use a common methodology, based on a regulatory body, postmarketing surveillance, risk management, post-approval research and enforcement [12]. In 2012 also E.U. has decided to apply MedDRA as a tool to standardize medical terminology.

In spite of these progresses, many underdeveloped countries do not have pharmacovigilance policies [22]. Even where there are such policies, as in EU and US, the effective rules of pharmacovigilance activities are different $[2,20,23]$. Even a basic concept such as Adverse Drug Reaction (ADR) is not the same. The Federal Food, Drug, and Cosmetic Act affirm that adverse drug experience is "any adverse event associated with the use of a drug in humans, whether or not considered drug related" (emphasis added) [24]. Instead, in accordance with the above mentioned definition of ADR provided by the E.U. legislation, the adverse event should be reported only if there is a reasonable possibility of causal relationship between a medicinal product and such adverse event. As a result, in the U.S. system of pharmacovigilance there should be more ADR than in the E.U. one. Therefore, the goal of creating a global pharmacovigilance that protect equally public health in many countries is still far.

\section{References}

1. Commission Staff Working Document (2008) Commission of The European Communities 9, 52

2. Wiktorowicz M, Lexchin J, Moscou K (2012) Pharmacovigilance in Europe and North America: divergent approaches. Soc Sci Med 75: 165-170.

3. WHO Policy Perspectives on Medicines (2004) Pharmacovigilance: Ensuring the Safe Use of Medicines. WHO, Geneva, Switzerland.

4. Directive 2010/84/EU of the European Parliament and of the Council of December 15, 2010 (2010). Official Journal of the European Union 378: 74-99.

5. Regulation (EU) No $1235 / 2010$ of the European Parliament and of the Counci of December 15, 2010 (2010). Official Journal of the European Union 348: 1-16.

6. Commission Implementing Regulation (EU) No 520/2012 of June 19, 2012 (2012). Official Journal of the European Union 159: 5-25.

7. Regulation (EU) No 1027/2012 of the European Parliament and of the Council of October 25, 2012 (2012). Official Journal of the European Union 316: 38-40.

8. Garattini S, Bertelè V (2011) Anything new in EU pharmacovigilance? Eur J Clin Pharmacol 67: 1199-1200.

9. Borg JJ, Aislaitner G, Pirozynski M, Mifsud S (2011) Strengthening and rationalizing pharmacovigilance in the EU: where is Europe heading to? A review of the new EU legislation on pharmacovigilance. Drug Saf 34: 187-197.

10. Callréus $T$ (2011) The new EU legislation on pharmacovigilance and changing models for drug development. Drug Saf 34: 529-530.

11. Food and Drug Administration Amendments Act of September 27, 2007

12. Faden LB, Milne CP (2008) Pharmacovigilance Activities in the United States, European Union and Japan: Harmonic Convergence or Convergent Evolution? Food Drug Law J 63: 683-700.

13. Frau S, Font Pous M, Luppino MR, Conforti A (2010) Risk Management Plans: are they a tool for improving drug safety? Eur J Clin Pharmacol 66: 785-790.

14. Prieto L, Spooner A, Hidalgo-Simon A, Rubino A, Kurz X, et al. (2012) Evaluation of the effectiveness of risk minimization measures. Pharmacoepid Drug Saf 21: 896-899.

15. Wilson A, Milne CP (2011) FDA's Risk Evaluation and Mitigation Strategies (REMS): Effective and Efficient Safety Tools or Process Poltergeist? Food Drug Law J 66: 569-585

16. Hanzl-Duimović I, Sulić-Milisić Z, Staresinić-Sernhorst I (2007) Issues with regulatory pharmacovigilance in East European countries: the industry perspective. Toxicol Lett 168: 228-235.

17. Kunac DL, Harrison-Woolrych M, Tatley MV (2008) Pharmacovigilance in New Zealand: the role of the New Zealand Pharmacovigilance Centre in facilitating safer medicines use. N Z Med J 121: 76-89.

18. Dasgupta N, Schnoll SH (2009) Signal detection in post-marketing surveillance for controlled substances. Drug Alcohol Depend 105: S33-S41.

19. Tsintis P, La Mache E (2004) CIOMS and ICH initiatives in pharmacovigilance and risk Management: overview and implications. Drug Saf 27: 509-517.

20. Castle GH, Kelly B (2008) Global Harmonization is not all that global: divergent approaches in drug safety. Food Drug Law J 63: 601-622.

21. ICH Harmonised Tripartite Guideline Pharmacovigilance Planning E2E (2004) International conference on Harmonisation of Technical Requirements for Registration of Pharmaceuticals for Human Use.

22. Persaud-Sharma V, Zhou SF (2013) Incorporation of New Technologies into Global Pharmacovigilance. J Pharmacovigilance 1: 1-5.

23. Lojko N (2010) Medicinal products in the European Union--between harmonization and divergence. Med Law 29: 61-76.

24. Section 355-1(b) Title 21- Food and Drugs, Federal Food, Drug, and Cosmetic Act, FDA, US Department of Health \& Human Services 158-199. 